\title{
PENGARUH EXPERIENTIAL MARKETING DAN SERVICE QUALITY TERHADAP CUSTOMER LOYALTY: CUSTOMER SATISFACTION SEBAGAI VARIABEL MEDIASI
}

\author{
Ika Nurul Febrianti \\ Program Studi Magister Manajemen Universitas Tarumanagara \\ ika.nurulfebrianti@yahoo.com \\ Keni \\ Program Studi Magister Manajemen Universitas Tarumanagara \\ Masuk : 26-05-2020, revisi : 26-06-2020 diterima untuk diterbitkan : 29-06-2020
}

\begin{abstract}
The aims of this study are four: first, to explore the effects of experiential marketing and service quality toward customer satisfaction. Second, to explore the effects of experiential marketing and service quality toward customer loyalty. Third, to explore the effects of customer satisfaction toward customer loyalty. Fourth, to find out the effects of experiential marketing and service quality toward customer loyalty if mediated by customer satisfaction. The samples that were collected were 154 respondents who are customers from one of food and beverage industry in Jakarta. The method of data collection is conducted by nonprobability sampling with the technique of convenience sampling through online questionnaires. The data were analysed by using PLS-SEM. The results of this research are: First, experiential marketing and service service quality have a positive impact toward customer satisfaction. Second, experiential marketing has a positive impact toward customer loyalty, but service quality does not have a positive impact toward customer loyalty. Third, customer satisfaction has a positive impact toward customer loyalty. Fourth, experiential marketing and service quality have a positive impact toward customer loyalty if mediated by customer satisfaction.
\end{abstract}

Abstrak : Tujuan dari penelitian ini ada empat : pertama menguji pengaruh experiential
marketing dan service quality terhadap customer satisfaction. Kedua, menguji pengaruh
experiential marketing dan service quality terhadap customer loyalty. Ketiga, menguji
pengaruh customer satisfaction terhadap customer loyalty. Keempat, menguji pengaruh
experiential marketing dan service quality terhadap customer loyalty bila dimediasi oleh
customer satisfaction. Sampel yang dikumpulkan adalah 154 responden yang merupakan
konsumen dari salah satu industri makanan dan minuman di Jakarta. Metode pengambilan data
adalah non-probability sampling dengan teknik convenience sampling melalui kuesioner
online. Analisis data menggunakan PLS-SEM. Hasil penelitian adalah: pertama, experiential
marketing dan service quality berpengaruh positif terhadap customer satisfaction. Kedua,
experiential marketing berpengaruh positif terhadap customer loyalty tetapi service quality
tidak memiliki pengaruh positif terhadap customer loyalty. Ketiga, customer satisfaction
memiliki pengaruh positif terhadap customer loyalty. Keempat, experiential marketing dan
service quality berpengaruh positif terhadap customer loyalty bila dimediasi oleh customer
satisfaction.

Keywords : Experiential Marketing, Service Quality, Customer Satisfaction, Customer Loyalty 


\section{PENDAHULUAN}

Di zaman modern ini perkembangan restoran cepat saji meningkat pesat. Dengan semakin banyaknya restoran yang menyajikan masakan khas Indonesia, para pelaku bisnis harus mempunyai strategi pemasaran yang baik dan efektif. Sehingga sebuah brand tidak mudah dilupakan dan menjadi pilihan utama dibandingkan brand lainnya. Dalam dunia bisnis konsumen adalah penentu keberlangsungan suatu usaha. Loyalitas pelanggan dianggap memiliki peranan penting karena merupakan salah satu cara untuk meningkatkan keuntungan penjualan perusahaan (Ma et al., 2014). Menurut Shin et al (2015), customer loyalty merupakan niat customer untuk terus menggunakan suatu penyedia layanan berdasarkan pengalaman customer selama menggunakan layanan di masa lalu dan harapan atas layanan di masa depan. Menurut Lee et al (2010), customer loyalty dipengaruhi oleh experiential marketing, service quality dan customer satisfaction.

Menurut Schmitt (1999), experiential marketing yaitu memberikan sebuah pengalaman kepada pelanggan pada saat menggunakan produk atau jasa melalui rangsangan pada unsurunsur emosi konsumen. Service quality adalah evaluasi terhadap kualitas hasil, interaksi dan lingkungan fisik yang dapat menimbulkan emosi positif dan negatif yang dapat mempengaruhi persepsi konsumen (Parasuraman et al., 2003). Menurut Marcell dan Adiwijaya (2017) perusahaan yang dapat memberikan pelayanan yang baik kepada pelanggan akan mendorong minat pelanggan untuk menggunakan jasa kembali sehingga tercipta loyalitas. Kim et al. (2004) menyatakan bahwa "satisfied customers exhibit loyalty". Semakin tinggi tingkat kepuasan yang dialami oleh konsumen maka loyalitas mereka terhadap sebuah produk atau jasa akan meningkat. Berdasarkan latar belakang tersebut, tujuan dari penelitian ini adalah untuk meneliti pengaruh experiential marketing dan service quality terhadap customer loyalty: customer satisfaction sebagai variabel mediasi.

\section{TELAAH KEPUSTAKAAN Experiential Marketing}

Menurut Kartajaya (2004: 166), experiential marketing adalah "suatu konsep pemasaran yang bertujuan untuk membentuk pelanggan-pelanggan yang loyal dengan menyentuh emosi mereka dan memberikan suatu feeling yang positif terhadap produk dan servis."

\section{Service Quality}

Menurut Ashraf et al. (2015: 455) service quality adalah "a measure of how well a service encounters compatibility with customer expectarion". Jadi dapat disimpulkan bahwa kualitas layanan adalah ukuran seberapa baik suatu layanan sehingga sesuai dengan harapan konsumen.

\section{Customer Satisfaction}

Menurut Tjiptono (2007), kepuasan pelanggan adalah perasaan pelanggan sebagai tanggapan emosional pada evaluasi terhadap pengalaman selama mengkonsumsi suatu produk atau jasa.

\section{Customer Loyalty}

Menurut Tjiptono (2011: 110), loyalitas pelanggan adalah "komitmen pelanggan terhadap suatu merk, toko atau pemasok berdasarkan sifat yang sangat positif yang tercermin dalam pembelian ulang yang konsisten".

\section{Kaitan antar Variabel}

\section{Experiential Marketing dan Service Quality berpengaruh positif pada Customer Satisfaction}

Menurut Wu \& Tseng (2014), Lee et al. (2010), serta Tetanoe dan Dharmayanti (2014) pengalaman yang baik terhadap suatu produk atau jasa yang dirasakan oleh pelanggan akan meningkatkan kepuasan. Kemudian, menurut penelitian yang dilakukan Quddus dan Hudrasyah (2014), Wantara (2015) dan Siddiqi (2011), pelanggan yang mendapatkan kualitas pelayanan yang tinggi akan lebih merasa puas jika dibandingkan pelanggan yang mendapatkan kualitas pelayanan yang rendah. 
$\mathrm{H}_{1 \mathrm{a}}$ : Experiential marketing berpengaruh positif terhadap customer satisfaction

$\mathrm{H}_{1 b}$ : Service quality berpengaruh positif terhadap customer satisfaction

2. Experiential Marketing dan Service Quality berpengaruh positif pada Customer Loyalty

Menurut Zena dan Hadisumarto (2012), Lee et al. (2010), serta Wu dan Tseng (2015) experiential marketing dapat memengaruhi customer loyalty. Dengan memberikan pengalaman kepada pelanggan bisa meningkatkan ikatan emosional dengan pelanggan sehingga membuat pelanggan menjadi loyal. Kemudian, menurut Wong dan Sohal (2003), Wantara (2015), dan Siddiqi (2011) kualitas pelayanan yang baik akan meningkatkan kepuasan pelanggan dan meningkatkan loyalitas pelanggan.

$\mathrm{H}_{2 \mathrm{a}}$ : Experiential marketing berpengaruh positif terhadap customer loyalty

$\mathrm{H}_{2 \mathrm{~b}}$ : Service quality berpengaruh positif terhadap customer loyalty

\section{Customer Satisfaction berpengaruh positif pada Customer Loyalty}

Menurut Wu dan Tseng (2014), Famiyeh et al. (2017), Hadiwidjaja dan Dharmayanti (2014), kepuasan muncul karena pelanggan mendapatkan hal yang mereka harapkan terhadap suatu produk dan jasa. Bila konsumen merasa puas oleh produk atau jasa yang diberikan, konsumen akan cenderung membentuk perilaku yang loyal terhadap perusahaan tersebut.

$\mathrm{H}_{3}$ : Customer satisfaction berpengaruh positif terhadap customer loyalty

\section{Customer Satisfaction dapat memediasi pengaruh positif Experiential Marketing dan} Service Quality terhadap Customer Loyalty

Menurut Lee et al. (2010), Lokito dan Dharmayanti (2013) serta Wu dan Tseng (2014), experiential marketing berfokus pada pengalaman konsumen, evaluasi pada situasi konsumsi serta rasionalitas dan emosionalitas konsumen. Semakin baik pengalaman yang dirasakan maka hal tersebut akan mempengaruhi tingkat kepuasan pelanggan. Dengan tingginya tingkat kepuasan pelanggan maka akan meningkatkan loyalitas pelanggan, membatasi pangsa pasar pesaing dan meningkatkan reputasi perusahaan. Kemudian menurut penelitian yang dilakukan Quddus dan Hudrasyah (2014), Lee et al. (2010) dan Siddiqi (2011), kepuasan pelanggan akan mempengaruhi loyalitas pelanggan.

$\mathrm{H}_{4 \mathrm{a}}$ : Customer satisfaction dapat memediasi pengaruh positif experiential marketing terhadap customer loyalty

$\mathrm{H}_{4 \mathrm{~b}}$ : Customer satisfaction dapat memediasi pengaruh positif service quality terhadap customer loyalty

\section{METODOLOGI PENELITIAN}

Desain penelitian ini adalah penelitian deskriptif dengan metode cross sectional design. Populasi dalam penelitian ini adalah seluruh konsumen salah satu restoran di Jakarta. Metode pengambilan sampel dalam penelitian ini adalah metode non-probability sampling dengan teknik convenience sampling. Sampel dalam penelitian ini sebesar 154 orang. Pengukuran objek penelitian diukur menggunakan skala Likert. Tabel 1 menunjukan pengukuran masingmasing variabel dan sumbernya, instrumen tersebut telah dilakukan analisis validitas dengan hasil analisis convergent validity dan discriminant validity. Sementara untuk analisis reliabilitas didasarkan pada nilai cronbach's alpha dan composite reliability. Metode analisis data dalam penelitian ini menggunakan structure equation modeling (SEM) dengan bantuan program SmartPLS 3.2.8. Taraf signifikansi yang digunakan pada penelitian ini adalah sebesar $5 \%$.

\section{Tabel 1}

Variabel Data Pengukuran

\begin{tabular}{|cl|c|l|}
\hline \multicolumn{1}{|c|}{ Variabel } & Jumlah Item & \multicolumn{1}{c|}{ Sumber } \\
\hline 1. & Experiential Marketing & $\mathbf{1 5}$ & Wijaya dan Subagio (2014), Tetanoe dan Dharmayanti (2014) \\
\hline 2. & Service Quality & $\mathbf{1 5}$ & $\begin{array}{l}\text { Zena dan Hadisumarto (2012), Jimanto dan Kunto (2014), } \\
\text { Winarta dan Kunto (2013) }\end{array}$ \\
\hline 3. & Customer Satisfaction & $\mathbf{3}$ & Leninkumar (2017), Lepojevic dan Dukic (2018) \\
\hline 4. & Customer Loyalty & $\mathbf{3}$ & \\
\hline
\end{tabular}




\section{HASIL UJI STATISTIK}

Hasil pengujian koefisien determinasi $\mathrm{R}^{2}$ dari penelitian ini menunjukan nilai presentase variabel customer satisfaction sebesar $0,631 \%$ artinya pengaruh experiential marketing dan service quality terhadap customer satisfaction sebesar $63,1 \%$. Selain itu, nilai $\mathrm{R}^{2}$ pada variabel customer loyalty adalah 80,6\% artinya pengaruh experiential marketing, service quality dan customer satisfaction terhadap customer loyalty sebesar $80,6 \%$. Berdasarkan hasil pengujian maka nilai $R$ square dalam penelitian ini tergolong moderat dan kuat (Henseler et al., 2009). Kemudian hasil pengujian predictive relevance $\left(\mathrm{Q}^{2}\right) 0,501$ dan $0,650\left(\mathrm{Q}^{2}>0\right)$ yang berarti bahwa konstruk variabel yang terdapat dalam penelitian ini relevan untuk mengukur model penelitian yang telah terbentuk sebelumnya dengan baik (Hair et al., 2011).

\section{Tabel 2}

\section{Hasil Pengujian Hipotesis}

\begin{tabular}{clccc}
\hline & \multicolumn{1}{c}{ Hipotesis } & Coefficient & T-statistic & p-values \\
\hline $\mathrm{H} 1 \mathrm{a}$ & Experiential Marketing -> Customer Satisfaction & 0,444 & 3,402 & 0,001 \\
\hline $\mathrm{H} 1 \mathrm{~b}$ & Service Quality -> Customer Satisfaction & 0,380 & 2,798 & 0,005 \\
\hline $\mathrm{H} 2 \mathrm{a}$ & Experiential Marketing -> Customer Loyalty & 0,566 & 5,135 & 0,000 \\
\hline $\mathrm{H} 2 \mathrm{~b}$ & Service Quality -> Customer Loyalty & $-0,174$ & 1,928 & 0,054 \\
\hline $\mathrm{H} 3$ & Customer Satisfaction -> Customer Loyalty & 0,543 & 7,442 & 0,000 \\
\hline $\mathrm{H} 4 \mathrm{a}$ & $\begin{array}{l}\text { Experiential->Customer Satisfaction } \\
\text {->Customer Loyalty }\end{array}$ & 0,241 & 3,105 & 0,002 \\
\hline $\mathrm{H} 4 \mathrm{~b}$ & $\begin{array}{l}\text { Service Quality->Customer Satisfaction } \\
\text {->Customer Loyalty }\end{array}$ & 0,206 & 2,563 & 0,011 \\
\hline
\end{tabular}

Dalam uji hipotesis untuk melihat variabel berpengaruh signifikan atau tidak adalah dengan melihat nilai t-statistic $>1,96$ dan nilai p-values $<0,05$. Berdasarkan Tabel 2. di atas dapat ditarik kesimpulan bahwa variabel experiential marketing berpengaruh sebesar 0,444 dan signifikan terhadap customer satisfaction. Service quality berpengaruh sebesar 0,380 dan signifikan terhadap customer satisfaction. Experiential marketing berpengaruh 0,566 dan signifikan terhadap customer loyalty. Service quality tidak memiliki kontribusi untuk berpengaruh terhadap customer loyalty karena path coefficient yang dihasilkan adalah $-0,174$, serta nilai t-statistic kurang dari 1,96 dan p-value lebih dari 0,05. Customer satisfaction berpengaruh sebesar 0,543 dan signifikan terhadap customer loyalty. Selain itu customer satisfaction dapat memediasi secara positif antara experiential marketing dengan customer loyalty dengan nilai sebesar 0,241. Customer satisfaction juga dapat memediasi secara positif antara service quality dengan customer loyalty dengan nilai sebesar 0,206. Dapat disimpulkan bahwa H1a, H1b, H2a, H3, H4a, dan H4b tidak ditolak sedangkan H2b ditolak.

\section{PEMBAHASAN}

Hasil pengujian hipotesis 1a membuktikan bahwa experiential marketing mampu mempengaruhi secara positif terhadap customer satisfaction. Dengan pengalaman yang menyenangkan selama bertransaksi maka pelanggan akan merasa puas. Hasil penelitian ini sejalan dengan penelitian yang telah dilakukan oleh Lee et al. (2010), Zena dan Hadisumarto (2012), dan Wu dan Tseng (2014).

Hasil pengujian hipotesis $1 \mathrm{~b}$ membuktikan bahwa service quality mampu mempengaruhi secara positif terhadap customer satisfaction. Di tengah tingginya persaingan dalam industri restoran cepat saji, perusahaan tentunya harus dapat memberikan pelayanan yang terbaik. Pelanggan yang mendapatkan kualitas pelayanan yang tinggi akan lebih merasa puas jika dibandingkan pelanggan yang mendapatkan kualitas pelayanan yang rendah. Hasil penelitian ini sejalan dengan penelitian yang telah dilakukan Zena dan Hadisumarto (2012), Famiyeh et al. (2017) dan Siddiqi (2011).

Pada hipotesis 2a yaitu experiential marketing mampu mempengaruhi secara positif terhadap customer loyalty. Dengan memberikan pengalaman kepada pelanggan dapat meningkatkan ikatan emosional sehingga membuat pelanggan menjadi loyal. Hasil penelitian 
ini sejalan dengan penelitian yang telah dilakukan Zena dan Hadisumarto (2012), Hadiwidjaja dan Dharmayanti (2014), serta Wu dan Tseng (2014).

Pada hipotesis $2 \mathrm{~b}$ yaitu service quality berpengaruh negatif terhadap customer loyalty, sehingga service quality tidak terbukti mampu mempengaruhi customer loyalty. Hasil penelitian yang dilakukan oleh Zena dan Hadisumarto (2012) sejalan dengan hasil penelitian, dimana service quality tidak memiliki pengaruh signifikan terhadap customer loyalty, tetapi memiliki pengaruh signifikan bila dimediasi oleh customer satisfaction.

Kemudian pada hipotesis ketiga yaitu customer satisfaction mampu mempengaruhi secara positif terhadap customer loyalty. Hasil penelitian ini sejalan dengan penelitian Lee et al. (2010), Famiyeh et al (2017), serta Lokito dan Dharmayanti (2013). Apabila konsumen merasa puas oleh produk atau jasa yang diberikan, konsumen akan cenderung membentuk perilaku yang loyal terhadap perusahaan tersebut.

Pada hipotesis 4a terbukti customer satisfaction dapat memediasi secara positif experiential marketing terhadap customer loyalty. Hasil penelitian ini sejalan dengan penelitian $\mathrm{Wu}$ dan Tseng (2014). Pengalaman yang baik terhadap suatu produk dan jasa yang dirasakan oleh pelanggan akan meningkatkan kepuasan. Selain itu, semakin tinggi tingkat kepuasan konsumen maka akan mempengaruhi loyalitas.

Pada hipotesis $4 \mathrm{~b}$ terbukti customer satisfaction dapat memediasi secara positif service quality terhadap customer loyalty. Hasil ini sejalan dengan penelitian Quddus \& Hudrasyah (2014) dan Wantara (2015). Pelanggan yang mendapatkan kualitas pelayanan yang tinggi akan lebih merasa puas jika dibandingkan pelanggan yang mendapatkan kualitas pelayanan yang rendah. Selain itu, dengan tingkat kepuasan terhadap kualitas pelayanan yang tinggi maka akan mempengaruhi loyalitas.

\section{KESIMPULAN DAN SARAN}

Kesimpulan yang dapat diambil berdasarkan hasil penelitian ini adalah experiential marketing dan service quality berpengaruh positif terhadap customer loyalty. Experiential marketing berpengaruh positif terhadap customer loyalty sedangkan service quality tidak berpengaruh positif terhadap customer loyalty. Customer satisfaction berpengaruh positif terhadap customer loyalty. Customer satisfaction berpengaruh positif dalam memediasi pengaruh positif experiential marketing dan service quality terhadap customer loyalty.

Hasil penelitian ini juga memberikan saran agar perusahaan dapat memberikan pengalaman yang baik untuk konsumen dan meningkatkan kualitas layanan selama konsumen melakukan pembelian di restoran. Dengan meningkatkan kedua hal tersebut konsumen akan merasa puas sehingga menciptakan pelanggan yang loyal.

\section{IMPLIKASI MANAJERIAL}

Berkaitan dengan hasil penelitian, maka dapat disampaikan beberapa implikasi manajerial yang dapat diterapkan oleh perusahaan. Melihat dari hasil pengaruh positif experiential marketing, customer satisfaction dan customer loyalty maka dihimbau agar perusahaan tetap konsisten dalam menciptakan pengalaman yang baik untuk konsumen. Hal yang dapat dilakukan adalah dengan menjaga kualitas makanan dan melakukan inovasi produk. Sedangkan untuk variabel service quality, perusahaan dihimbau untuk lebih memperhatikan kualitas layanan sehingga mampu meningkatkan loyalitas pelanggan. Hal yang perlu diperhatikan adalah tampilan fasilitas secara fisik, peralatan dan penampilan karyawan. Selain itu kemampuan karyawan dalam melayani konsumen juga perlu ditingkatkan.

\section{DAFTAR PUSTAKA}

Ashraf, et.al. (2015). Impact of Service Quality, Corporate Image and Perceived Value on Brand Loyalty with Presence and Absence of Customer Satisfaction : A Study of Four 
Service Sectors of Pakistan. International Journal of Academic Research in Business \& Social Sciences, 8.

Famiyeh, S., Darko, D.A., Kwarteng, A. (2017). Service Quality, Customer Satisfaction, and Loyalty in the Banking Sector. International Journal of Quality \& Reliability Management, 35 (8).

Hadiwidjaja, R. S. \& Dharmayanti, D. (2015). Analisa Hubungan Experiential Marketing, Kepuasan Pelanggan, Loyalitas Pelanggan Starbucks Coffee di Surabaya Town Square. Jurnal Manajemen Pemasaran, 2 (2).

Hair, et. al. (2011). Multivariate Data Analysis (7th ed.). New Jersey : Pearson Prentice Hall.

Henseler, Jorg, Christian M. Ringle \& Marko Sarstedt. (2009). Using Partial Least Squares Path Modeling in Advertising Research : Basic Concepts and Recent Issues. Handbook of Research in International Advertising.

Kartajaya, Hermawan. (2004). Hermawan Kartajaya on Marketing. Jakarta : PT. Gramedia Pustaka Utama.

Kim, M.K., Park, M.C., \& Jeong, D.H. (2004). The Effects of Customer Satisfaction and Switching Barrier on Customer Loyalty in Korean Mobile Communication Services. Telecommunications Policy, 28 (2), 145-159.

Lee, Ming-Shing, Huey-Der Hsio \& Ming-Fen Yang. (2010). The Study of The Relationships Among Experiential Marketing, Service Quality, Customer Satisfaction and Customer Loyalty. International Journal of Organizational Innovation.

Lokito, S. A. \& Dharmayanti, D. (2013). Analisis Pengaruh Experiential Marketing dan Customer Satisfaction terhadap Customer Loyalty Comedy Kopi di Surabaya. Jurnal Strategi Pemasaran, 1 (2).

Marcell, \& Michael Adiwijaya. (2017). Pengaruh Dimensi Kualitas Layanan terhadap Loyalitas Pelanggan di Auto Bridal Surabaya. Agora, 5 (1).

Parasuraman, A., Zeithaml, V. A. \& Berry, L. L. (2003). A Conceptual Model of Service Quality and It's Implications for Future Research. Journal of Marketing, 4.

Quddus, F. S., \& Hudrasyah, H. (2014). The Influences of Service Quality Dimensions on Customer Satisfaction and Customer Loyalty in PT. JNE North Bandung Area. Journal of Business and Management.

Schmitt, Bernd. (1999). Experiential Marketing. New York : The Free Press.

Siddiqi, Kazi Omar. (2011). Interrelations between Service Quality Attributes, Customer Satisfaction and Customer Loyalty in the Retail Banking Sector in Bangladesh. International Journal of Business and Management, 6 (3).

Tetanoe, V. R. \& Dharmayanti, D. (2014). Pengaruh Experiential Marketing terhadap Pembelian Ulang dengan Kepuasan Pelanggan sebagai Variable Intervening di Breadtalk Surabaya Town Square. Jurnal Manajemen Pemasaran Petra, 2 (1).

Tjiptono, Fandy. (2007). Strategi Pemasaran. Yogyakarta : Andi Offset.

Wantara, Pribanus. (2015). The Relationships among Service Quality, Customer Satisfaction and Customer Loyalty in Library Services. International Journal of Economics and Financial Issues.

Wong, Amy \& Sohal, Amrik. (2003). Service Quality and Customer Loyalty Perpectives on Two Levels of Relationships. Journal of Services Marketing, 17 (5).

Wu, Mei-Ying \& Tseng, Li-Hsia. (2015). Customer Satisfaction and Loyalty in an Online Shop : An Experiential Marketing Perspective. International Journal of Business and Management, 10 (1).

Zena, P. A., \& Hadisumarto, A. D. (2012). The Study of Relationship Among Experiential Marketing, Service Quality, Customer Satisfaction, and Customer Loyalty. Asean Marketing Journal. 